\title{
COMMENTARY
}

\section{Open visitation policies and practices in US ICUs: can we ever get there?}

Jennifer L McAdam ${ }^{1}$ and Kathleen A Puntillo*2

See related research by Liu et al., http://ccforum.com/content/17/2/R71

\begin{abstract}
Open visitation has been highly recommended by critical care groups but is not prevalent in practice. Here we discuss the present study on current visitation practices in US ICUs and discuss several factors affecting open visitation. We conclude with suggestions on achieving more liberal visitation practices.
\end{abstract}

In a previous issue of Critical Care, Liu and colleagues embark upon a timely and important topic: visitation practices in US ICUs [1].

There are many benefits to open visitation. Patients feel supported [2] and safe [3]. Families are more satisfied with care and are less anxious [4]. Healthcare providers have increased opportunities for communication and teaching [2]. Because of these benefits, open and unrestricted visitation in ICUs has been recommended by critical care groups $[5,6]$. However, Liu and colleagues report that almost all US ICUs (90\%) have restrictive visitation policies, and most (62\%) have three or more restrictions. What is disconcerting is that these findings are not all that different from those reported in 2007, where only $32 \%$ of ICUs had open visitation [7]. Even this statistic is misleading, because 'open' referred only to the hours of visitation, and most ICUs considered open had restrictions on age and the number of visitors [7]. Liu and colleagues' findings are also consistent with those from other countries where very few, if any, ICUs have open visitation policies $[8,9]$. With all of the evidence guiding practice toward open visitation, why is it that most ICUs continue to have restrictions on visitation? There are

*Correspondence: kathleen.puntillo@nursing.ucsf.edu 2Department of Physiological Nursing, University of California, San Francisco, 2 Koret Way, Box 0610, San Francisco, CA 94143-0610, USA

Full list of author information is available at the end of the article several factors to be considered before ICUs truly embrace open visitation.

One factor is the ICU patient. Open visitation has been studied from the perspective of the family and the healthcare provider, but very few studies have focused on the patient's perspective. Because ICU patients are often unable to communicate their preferences about visitation, they are often excluded from research studies. However, Olsen and colleagues interviewed 11 ICU patients to gain their perspective on visitation [10]. These patients stated that they felt supported when their families were present and were in favor of flexible visitation. Yet most patients wanted some limitations, such as having only close family members visit. In addition, these patients felt stressed when trying to communicate with visitors and when thinking about how upsetting this experience was for their families [10]. Recently, Hardin and colleagues surveyed 122 ICU patients on their satisfaction with unrestricted visiting hours [11]. Their results support those of Olsen and colleagues, since most patients wanted some restrictions and control over visitation. These two studies on the patient's perspective indicate that the patient's voice needs to be heard when developing visitation policies.

Another factor is the potential contributions of visiting ICU family members to the well-being of their loved ones. Interviews of 25 family members of 24 high risk of dying ICU patients showed that families took on certain roles while in the ICU and that they were physically and actively present in their loved ones' care [12]. These families reported that they were physically and actively present in their loved ones' care. Families' contributions included protecting the patient, facilitating information, providing necessary patient history, comforting and motivating the patient, and performing caregiving activities. As a result, families believed the patient felt safer and more supported if they were present. Others have found that families can contribute to patient care by keeping ICU diaries for the patient [13]. In families that kept diaries, researchers reported significantly lower post-traumatic stress symptoms in both patients and family members 12 months after the ICU stay [13]. 
Families can also contribute to patient care by participating in patient rounds. Investigators assessing this approach reported improved family satisfaction with communication and decision-making, both of which are important needs for families [14]. Families have much to offer, and allowing them open visitation could help them fulfill their roles, contribute to patient care, and decrease patient and family symptoms.

One more factor is the healthcare provider. In a study comparing healthcare providers' beliefs and attitudes toward open visitation, researchers found that nurses were generally not in favor of it [15]. Nurses feared losing control of their ICU room and felt that visits did not offer more comfort and support to the family. They also felt that open visitation hindered patient rest, infringed on patient privacy, and was an impediment to the nurses doing their job [15]. In addition, there is a great deal of inconsistency among healthcare providers in the level of comfort they have in communicating with families. For example, those who feel more comfortable working with families may favor open visitation, whereas those who do not may want stricter visitation policies. Liu and colleagues found this lack of consistency to be the case, with more restrictions in the Northeast and fewer restrictions in the Midwest and smaller hospitals [1]. This lack of consistency, along with varying beliefs and attitudes toward visitation, can lead to confusion and resentment to all involved (patient, family and healthcare provider) and may be another factor as to why open visitation policies in ICUs continue to be elusive.

So how do ICUs embrace open visitation? First, it should be understood that open visitation is not a onesize-fits-all philosophy. Second, it should be clarified that open visitation does not mean a free-for-all, with visitors being on the unit whenever they like. Third, it is important to understand that addressing visitation is a complex process that means patient interests are accounted for, clinicians have improved communication skills, and families are supported and prepared for their visits. Fourth, changing the terms 'open' and 'unrestricted' to 'flexible' and 'liberal' could help alleviate some of the barriers that healthcare providers have toward open visitation. Finally, perhaps each ICU will need to have an individualized approach to open visitation policies that meet the needs of the patient, the family, and the healthcare provider. However ICUs choose to embrace open visitation, it needs to happen.
Competing interests

The authors declare that they have no competing interests.

\section{Author details}

'Samuel Merritt University, School of Nursing, 3100 Summit Street, Oakland, CA 94609, USA. ${ }^{2}$ Department of Physiological Nursing, University of California, San Francisco, 2 Koret Way, Box 0610, San Francisco, CA 94143-0610, USA.

Published: 31 July 2013

\section{References}

1. Liu V, Read JL, Scruth E, Cheng E: Visitation policies and practices in US ICUs. Crit Care 2013, 17:R71

2. Kleinpell RM: Visiting hours in the intensive care unit: more evidence that open visitation is beneficial. Crit Care Med 2008, 36:334-335.

3. Gonzalez CE, Carroll DL, Elliott JS, Fitzgerald PA, Vallent HJ: Visiting preferences of patients in the intensive care unit and in a complex care medical unit. Am J Crit Care 2004, 13:194-198.

4. Garrouste-Orgeas M, Philippart F, Timsit JF, Diaw F, Willems V, Tabah A, Bretteville G, Verdavainne A, Misset B, Carlet J: Perceptions of a 24-hour visiting policy in the intensive care unit. Crit Care Med 2008, 36:30-35.

5. Davidson JE, Powers K, Hedayat KM, Tieszen M, Kon AA, Shepard E, Spuhler V Todres ID, Levy M, Barr J, Ghandi R, Hirsch G, Armstrong D; American College of Critical Care Medicine Task Force 2004-2005, Society of Critical Care Medicine: Clinical practice guidelines for support of the family in the patient-centered intensive care unit: American College of Critical Care Medicine Task Force 2004-2005. Crit Care Med 2007, 35:605-622.

6. Family presence: visitation in the adult ICU. Crit Care Nurse 2012, 32:76-78.

7. Lee MD, Friedenberg AS, Mukpo DH, Conray K, Palmisciano A, Levy MM: Visiting hours policies in New England intensive care units: strategies for improvement. Crit Care Med 2007, 35:497-501.

8. Hunter JD, Goddard C, Rothwell M, Ketharaju S, Cooper H: A survey of intensive care unit visiting policies in the United Kingdom. Anaesthesia 2010, 65:1101-1105.

9. Vandijck DM, Labeau SO, Geerinckx CE, De Puydt E, Bolders AC, Claes B, Blot SI; Executive Board of the Flemish Society for Critical Care Nurses, Ghent and Edegem, Belgium: An evaluation of family-centered care services and organization of visiting policies in Belgian intensive care units: a multicenter survey. Heart Lung 2010, 39:137-146.

10. Olsen KD, Dysvik E, Hansen BS: The meaning of family members' presence during intensive care stay: a qualitative study. Intensive Crit Care Nurs 2009, 25:190-198.

11. Hardin SR, Bernhardt-Tindal K, Hart A, Stepp A, Henson A: Critical-care visitation: the patients' perspective. Dimens Crit Care Nurs 2011, 30:53-61.

12. McAdam JL, Arai S, Puntillo KA: Unrecognized contributions of families in the intensive care unit. Intensive Care Med 2008, 34:1097-1101.

13. Garrouste-Orgeas M, Coquet I, Périer A, Timsit JF, Pochard F, Lancrin F, Philippart F, Vesin A, Bruel C, Blel Y, Angeli S, Cousin N, Carlet J, Misset B: Impact of an intensive care unit diary on psychological distress in patients and relatives. Crit Care Med 2012, 40:2033-2040.

14. Jacobowski NL, Girard TD, Mulder JA, Ely EW: Communication in critical care: family rounds in the intensive care unit. Am J Crit Care 2010, 19:421-430.

15. Biancofiore G, Bindi LM, Barsotti E, Menichini S, Baldini S: Open intensive care units: a regional survey about the beliefs and attitudes of healthcare professionals. Minerva Anestesiol 2010, 76:93-99.

\section{doi:10.1186/cc12763}

Cite this article as: McAdam JL, Puntillo KA: Open visitation policies and practices in US ICUs: can we ever get there? Critical Care 2013, 17:171. 